\title{
A Chemistry Based Service-Learning Course in New Orleans: Increasing Student Interest and Self-Efficacy in STEM
}

Ryan Vik ${ }^{\ddagger 1}$, Emily Schmidt ${ }^{\ddagger 1}$, Cooper H. Battle ${ }^{1,2}$, Janarthanan Jayawickramarajah ${ }^{*}, 1$

$\ddagger$ These authors contributed equally to the work.

${ }^{1}$ Department of Chemistry, Tulane University, 2015 Percival Stern Hall, New Orleans, Louisiana 70118, United States

${ }^{2}$ Department of Chemistry, Willamette University, 900 State St., Salem, Oregon, 97301, United States.

ABSTRACT: An important problem in STEM education is the low student retention rate. Non-traditional science courses that utilize more active-participation and learning are attractive as tools to increase student persistence and interest in STEM. Herein is described the content and implementation of a chemistry-based service-learning course that was offered in Spring 2019. The course features a well-rounded curriculum and diverse activities. The enrolled undergraduate students were not only taught chemistry concepts (general chemistry and supramolecular chemistry) but were also asked to present the chemical concepts using attention-grabbing demonstrations to public-school students in the New Orleans area. In addition, the course covered multiple non-science topics, including the pedagogy of service learning, background on the New Orleans public-school system, and how to work with the community. The

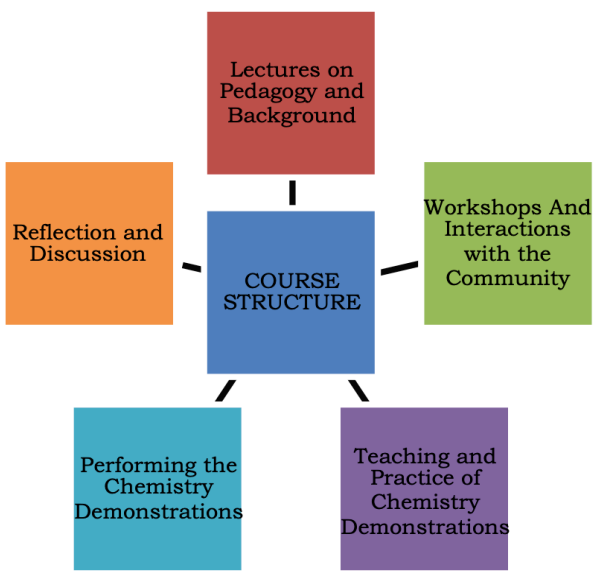
course also involved targeted student reflection activities/surveys and interfaced with the Tulane Center for Public Service. Results from a paired set of anonymous "before and after" student surveys lead us to suggest that the undergraduate students exhibited an increased desire towards STEM careers. The students also expressed, in general, higher confidence in the retention of chemical concepts that this course taught when compared to concepts retained from a standard general chemistry lab course. As importantly, this course provided the opportunity for students to engage with members of the New Orleans community.

\section{KEYWORDS}

First-Year Undergraduate, General, Elementary/Middle School Science, Demonstrations, Public understanding, service-learning, outreach, collaborative/cooperative learning, hands-on learning, reactions, rate law, physical properties, oxidation/reduction.

\section{INTRODUCTION}

40 Jobs that require fluency and training in Science, Technology, Engineering, and Mathematics (STEM) are becoming increasingly more salient in the modern global economy. It is estimated that, in 2018, 19.4 million jobs in the United States required at least some expertise in STEM fields ${ }^{1}$. The growth rate of STEM-aligned jobs are significantly larger (3-fold higher from 2000 to 2010) than the corresponding rate of non-STEM related jobs ${ }^{2}$. Even jobs with a less direct STEM focus, such as manufacturing, now require greater STEM training. Indeed, it is predicted that the United States will need to fill about 4.6 million manufacturing jobs by the year 2028. However, as many as 2 million of those jobs are projected to go unfilled due, in part, to a lack in the necessary technology training within the workforce ${ }^{2-5}$. Major reasons for the paucity of workers with the appropriate STEM skills required to access these attractive jobs include a lack of initial interest and decreased persistence in STEM fields ${ }^{6-8}$. Indeed, 
one study demonstrated that $40 \%$ of students who enter with a STEM major either change their field of study or leave college entirely ${ }^{8}$. Thus, in addition to cultivating an interest in STEM, the retention of students desiring STEM education is a challenge that must be addressed. Significant factors responsible for the low student retention rates in STEM include students' feelings of inadequate self-efficacy for $\mathrm{STEM}^{9}$, a lack of enthusiasm in the material ${ }^{10}$, and insufficient support systems. In the subject of chemistry, in particular, the retention rates are especially problematic. Chemistry courses have been cited as a main reason for students dropping out of their intended STEM career ${ }^{6,11,12}$. This is especially pronounced for underrepresented minorities in STEM ${ }^{11}$. As such, chemistry is a prime target for 80 intervention when aiming to increase student retention in STEM.

Various non-traditional chemistry course models have been implemented in recent years to address student interest and self-efficacy in STEM and enhance student learning ${ }^{13-16}$. Many of these courses center on active learning; a transition from purely lecture based material to including more discussion and hands-on interaction ${ }^{17,18}$. Examples of classroom models

90 that focus on active learning include peer-led team learning ${ }^{16}$ and flipped classrooms ${ }^{15}$. Service-learning is another non-traditional course model that uses active learning of material coupled with student engagement in the neighboring communities $17,19,20$. A major premise of service-learning is merging both serving and learning from the community, while concurrently mastering material related to the target subject. As such, service-learning is distinguished from community outreach or internships, which typically are not multifaceted $^{21}$. Importantly, participation in service-learning has been shown to boost student performance in academic measures

105 such as higher GPAs, better writing skills, and increased critical thinking ${ }^{22}$. Furthermore, after the completion of the service-learning courses, it has been shown that there is a marked increase in plans for additional community 110 engagement, regardless of initial student intent with respect to community involvement ${ }^{22}$. Service-learning has been adopted by many disciplines, including but not limited to, the humanities ${ }^{23}$, geology ${ }^{24}$, environmental science

115 25, and the physical sciences ${ }^{13}$ even chemistry ${ }^{13,14,26}$.
The state of Louisiana is poorly ranked among the United States under various school benchmarks for STEM performance 27,28 .

120 Further, in the city of New Orleans, 83 percent of students in the public education system come from economically disadvantaged backgrounds ${ }^{29-31}$ [footnote: as defined by being on free or reduced cost lunch programs].

125 Additionally, Hurricane Katrina greatly affected the schooling opportunities in New Orleans. Many buildings were destroyed forcing schools to relocate or shut down, and teachers were displaced or not rehired, losing a great deal of 130 expertise. As of 2018 , over $50 \%$ of teachers in the city have less than 5 years of professional experience and $73 \%$ have less than $10^{29,32}$. Accordingly, during the aftermath of Hurricane Katrina there was a genuine need for the 135 implementation of a service-learning course with the goal of increasing STEM engagement and excitement in the New Orleans area.

Here we describe the content and implementation of a chemistry-based service-

140 learning course (Chemistry 1898: Chemistry Outreach in New Orleans) involving undergraduate students from Tulane University engaging with students in the New Orleans public school system by both visiting schools to

145 conduct chemical demonstrations and hosting students at Tulane. We also detail how the course has served to sustain the undergraduate students' interest in STEM and STEM related careers, as well as increasing their public 150 speaking skills, confidence in understanding chemistry concepts and ultimately, their selfefficacy. The essential benefits brought to the service-learning course via collaboration with the Tulane Center for Public Service (CPS) is also delineated.

\section{BACKGROUND}

History of CHEM 1898 at Tulane

160 Given the above-discussed national issues on STEM retention and localized problems associated with New Orleans/Louisiana, we were eager to develop a STEM based servicelearning course. Prof. Janarthanan

165 Jayawickramarajah, along with graduate TAs, has taught and fine-tuned the course since 2009. Throughout these years, a number of New Orleans schools have been targeted including ReNEW SciTech, Phillis Wheatley (formerly John

170 Dibert), Lusher Charter School, Audubon Charter School, and Eleanor McMain Secondary 
School. Figure 1 shows the locations of the schools and after school programs that were involved. In general, the New Orleans public school population is mostly composed of underrepresented groups in STEM $(80 \%$ of public school students in New Orleans are African American ${ }^{29,31}$ ).

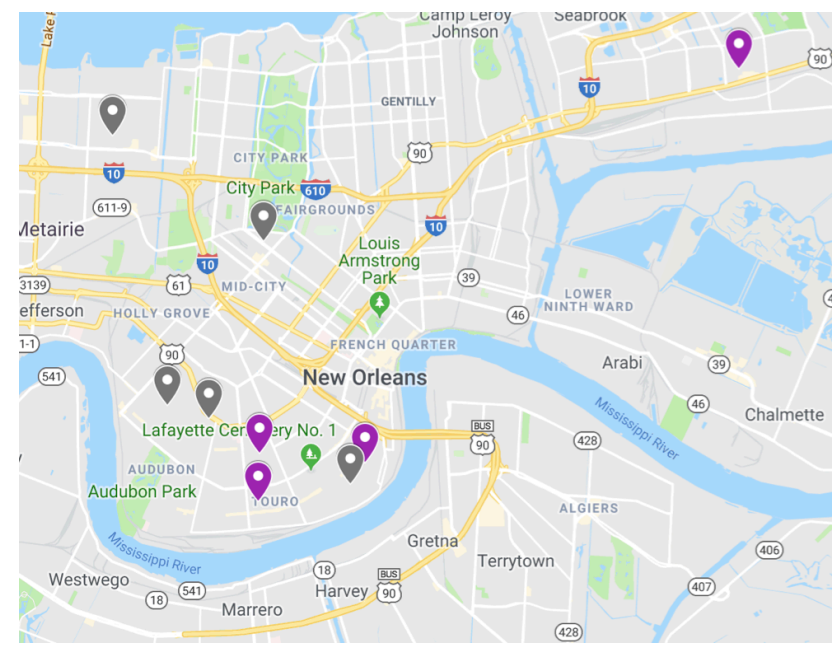

Figure 1. A map of New Orleans with the schools and programs involved with CHEM 1898. The purple markers are partner schools from Spring 2019, and grey markers indicate partners from past years. (Map data: Google, INEGI)

Although the details of our efforts for the earlier years are beyond the scope of this manuscript, some of the key challenges encountered and how they were addressed are highly instructive and thus will be discussed in the background section. The major focus of this the Spring Semester of 2019-the most recent iteration of the course.

Coupled with the need for increasing STEM interest and persistence, a major Renewal Plan 33 was introduced by Tulane University in 2006. The Plan focused on increasing community engagement by the University as a whole to enhance Tulane student outcomes and to complement Tulane's education and research 195 programs. As part of this plan, a mandatory service requirement was enacted, involving both a lower tier (20 hours of service) and an upper tier (40-hours of service). Chemistry 1898 fulfills the lower tier requirement. Due to the increased 200 number of service opportunities at Tulane, the CPS was created to oversee and aid servicelearning courses in addition to leading and assisting other community engagement opportunities ${ }^{34-36}$. CHEM 1898 has benefited from interfacing with the CPS and this interaction is detailed in the relevant sections.

\section{Choosing Partnerships}

Before initiating a service-learning program it is

210 important to find suitable partners. When determining a suitable partner for this course, we must identify schools and students that would genuinely benefit from the science demonstrations that we are providing. In Spring

215 2019, we targeted public school students from Lawrence D. Crocker College Prep, ReNew Schaumberg, Audubon Charter, and Elevate New Orleans. As can be seen from Table 137, these schools have a large population of 220 underrepresented groups in STEM and have low mastery of science as judged by the Louisiana Educational Assessment Program (LEAP) scores. From the standpoint of the undergraduates, it is imperative that the

225 community partner is able to provide multiple possible contact opportunities (i.e., time slots) to minimize time conflicts that might limit participation.

From year to year, a major concern is 230 maintaining partnerships with teachers within the New Orleans education system. Due to a teacher shortage in New Orleans, many teachers

Table 1. Comparison of the community partners who worked with CHEM 1898 Spring $2019^{37}$.

\begin{tabular}{|c|c|c|c|}
\hline & Audubon Charter & $\begin{array}{l}\text { Lawrence D. Crocker College } \\
\text { Prep }\end{array}$ & ReNEW Schaumburg \\
\hline Free/reduced lunch & $41.4 \%$ & $95.3 \%$ & $95.9 \%$ \\
\hline African American students & $45.4 \%$ & $88.8 \%$ & $95.5 \%$ \\
\hline $\begin{array}{l}\text { Students scoring mastery in } \\
\text { science }\end{array}$ & $37.0 \%$ & $10.0 \%$ & $7.0 \%$ \\
\hline Grade level & $4^{\text {th }}$ grade & $1-4^{\text {th }}$ grade & $5^{\text {th }}$ grade \\
\hline Partnership formation & Previous association & CPS & CPS \\
\hline
\end{tabular}


are from short-term programs such as Teach for America $^{29,38-40}$. In 2015, the Education Research Alliance report stated that nearly $25 \%$ of teachers were leaving either the profession or New Orleans annually38. Regular teacher turnover means new partnerships must be continuously formed, hindering the

240 development of long-term relationships and disrupting project expansion and specialization. Indeed, prior to 2019 , we had observed the loss of 5 partners in 8 years.

One natural solution would be to form relationships with less transient administrators in these schools instead. However, as the New Orleans public school system has transitioned to an increasingly charter-based system $(100 \%$ as of the summer of 201941,42), where different

250 charters can have completely different structures, navigating the differing systems can be difficult when reaching out. Several attempts in the past to contact school administrators were completely unanswered, or responses stopped before a visit was arranged.

In part to address the above issues, the course has cooperated with the Tulane CPS. CPS has been able to devote time and resources to creating and maintaining connections with New Orleans community partners. In addition, the CPS provided 4 other key support systems for this course: undergraduate student preparation, class evaluations, modest funding for course supplies, and additional service opportunities.

\section{Developing Chemistry Demonstrations}

The introductory courses to a subject are often a deciding factor in a student's persistence in

270 that field. ${ }^{35}$ For this reason, CHEM 1898 was designed to incorporate introductory general chemistry material to reinforce the Tulane students' understanding of these concepts and to improve their self-efficacy. The specific topics included thermodynamics, reaction kinetics, phase changes, oxidation/reduction and an introduction to non-covalent interactions and supramolecular chemistry (in the context of fluorescence and the hydrophobic effect).

280 However, the grade level of the public-school students had to be considered as well. Accordingly, demonstrations were purposely crafted such that explanations and concepts could be readily tuned to a variety of age groups.

285 As can be seen from Table 1, during Spring 2019, we worked with school students from grades 1 through 5 (Elevate New Orleans students were $7^{\text {th }}$ and $8^{\text {th }}$. While the first few years of the program mainly involved high school students, from 2014 to present CHEM 1898 has mainly presented demonstrations for audiences from grades 4-8. Some early exposure to STEM involving practical applications and projects, is important for future interest in 295 STEM fields. 43

In addition to tuning the demonstrations to reflect the age group targeted, another important factor that needs to be taken into consideration is the safe transportation, 300 presentation, and clean-up of demonstration materials. A good demonstration for this course involves minimal hazards (such as normal household products, like isopropyl alcohol used in the density rainbow) and is easily 305 transported, usually involving minimal and easily carried supplies.

As such, some demonstrations (e.g. nylon polymer synthesis) were set aside as they involved chemicals with greater hazards for an 310 open classroom environment (e.g. chemicals used during the polymer synthesis such as $\mathrm{NaOH}$, hexamethylaminediamine, sebacoyl chloride \& hexane) and necessitated transportation of both organic and aqueous

315 waste from the school for proper disposal.

\section{Course Setting and Enrollment Statistics}

The course was conducted at Tulane University; a medium sized private research university in

320 the southeastern United States. For the year of 2018-2019, the Institution had 8,610 undergraduates and 14,062 students total. The demographics of the university's first-year class was $72.39 \%$ Caucasian, 3.72\% African 325 American, 5.34\% Asian, 8.64\% Hispanic, and $3.98 \%$ identified as multiracial. From the same first-year class, $62.57 \%$ are female and $37.43 \%$ are male. ${ }^{44}$ CHEM 1898 primarily enrolled students who have already completed General 330 Chemistry I in the previous semester and are currently enrolled in General Chemistry II. As such the vast majority of the class are freshmen. In Spring 2019, the course had 15 students of which 80\% were female and 20\% male, 335 indicating a predominance of students in the course come from groups under-represented in STEM.

Since the students taking the course were mainly freshmen, their final major of choice had 340 not been solidified yet (at Tulane the deadline to 
choose a major is the fourth semester). However, the general career aspirations of the students were gauged by a survey (results in Figure 2, survey included in supplemental). The course was mainly made up of students who were interested in pre-professional related healthcare, with some students showing interest in engineering, and research in general.

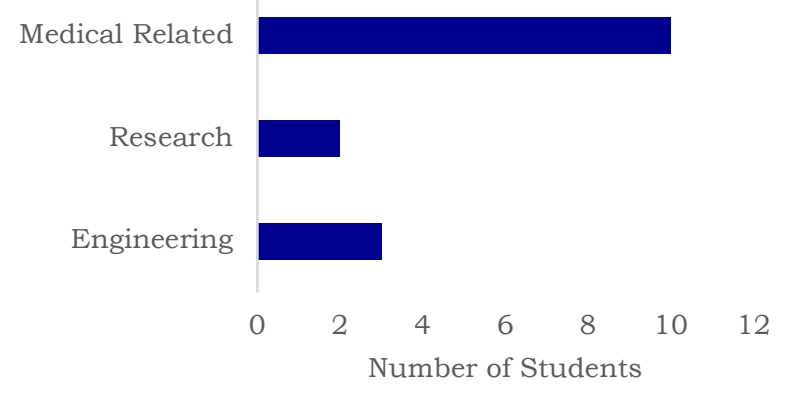

Figure 2: Career Aspirations as indicated in the before survey.

\section{COURSE GOALS}

CHEM 1898 was designed to promote interest in chemistry and STEM in the New Orleans area. In particular, a goal was to engender excitement about chemistry among local public-school students by illustrating fundamental concepts in chemistry through interesting and stimulating demonstrations. Furthermore, the course also was designed to enhance and sustain interest in STEM for the Tulane undergraduate students. Moreover, while conducting the demonstrations the undergraduates also are required to explain the key concepts of the demonstrations using clear and simple language. Hence, this active learning activity enables the students to have a more solid and mature understanding of the material taught in General Chemistry. As part of their explanation, the undergraduate students were encouraged to illustrate how fundamental chemistry knowledge can be linked to real world applications $^{6}$.

Unlike a traditional chemistry course, this service-learning course also provides an opportunity for the undergraduate students to master a wider range of skills outside of chemistry. For example, public speaking is a specific skill that the course teaches the students. Furthermore, the course also provided

380 a history and discussion on why there is a need for this specific STEM-related service-learning activity. In particular, discussions were focused on educational disparity in the US and the need for STEM in a modern society/economy. Hence,

385 CHEM 1898 was also expected to help the Tulane students develop a sense of civic responsibility/activism.

Implementation

390 This course met regularly for a one-hour period every week. The seminal meeting was an introduction to the course and discussion about the syllabus, followed by icebreaking activities. As outlined in Figure 3, CHEM 1898 was divided into the five subsections.

The first subsection was an introduction to the pedagogy of service-learning and a general background on the New Orleans K-12 education system. These initial lectures provided an 400 opportunity for the undergraduate students to learn about the course goals and the needs of the community. The lectures also covered pedagogical concepts within service-learning. Following this, the course transitioned to a 405 series of lectures that discussed historical injustices in the educational system in the US, by covering such topics as Plessy v. Ferguson and Brown v. Board of Education. Next, the topics shifted to pertinent issues localized in the

410 New Orleans public education system. In order to enhance active learning, the students were encouraged to discuss with their classmates on

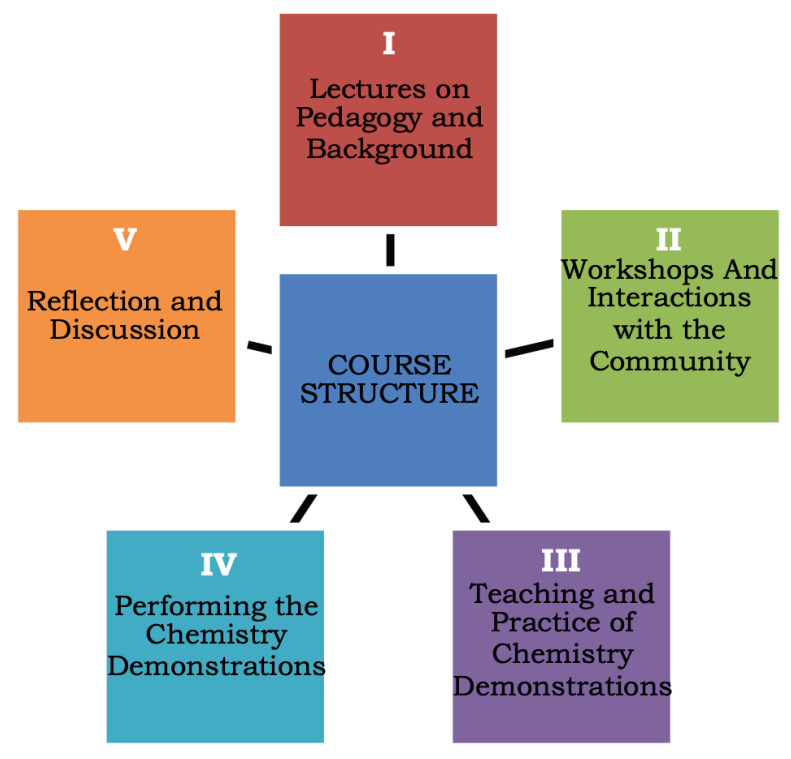

Figure 3. The five subsections of the course. 
how to resolve issues pertaining to STEM education.

The second subsection was composed of a series of workshops that equipped the undergraduate students in thinking about how to properly and respectfully interact with the public-school students. In terms of socioeconomic and demographic standpoints, the background of many of the undergraduate students are substantially different from students in the local public schools. This disparity in background was specifically demonstration activities. In order to mitigate problems that can arise when volunteers enter a different community, a specific training session was held. In particular, TAs from the CPS led a workshop on "Entering Communities" that focused on working with youth. Here, the Tulane students were encouraged to examine concepts including privilege, microaggressions, and respectful engagement with other communities.

In addition, community partners (e.g. the Academic Coordinator of Elevate New Orleans) were invited to spearhead discussions on specific problem areas including the lack of accessible equipment for interactive chemistry and other science, the need for educational outreach, and possible solutions in the local education community. Further, a discussion was hosted by the coordinator for Tulane's K-12 STEM Outreach program in which the greater educational parity in New Orleans were discussed. Taken together, these events enabled the students to gain a deeper understanding

about the New Orleans community, issues pertaining to STEM education, and served to initiate a partnership between the undergraduate students and the community.

The third subsection of the course involved reinforcing key chemistry concepts important to each demonstration through a combination of readings, discussions, and experiential learning in a lab setting. The students were given guidelines for each demonstration and, under the supervision of the graduate student TAs, practiced going through each demonstration while explaining the underlying chemical concepts. Following this practice, they were encouraged to discuss with their partners how to best explain and demonstrate the activities for their target student audience. This generated more exposure to each subject and helped the undergraduates learn to explain the topics in relatable ways.

The fourth subsection involved the active service component of the course. This subsection served to not only introduce or reinforce chemistry concepts to the K-12 students but also allowed the undergraduates to apply chemistry knowledge in a practical setting. This opportunity was designed to foster interest in STEM among the public-school students through interesting visual effects and interactive demonstrations.

Visiting the schools allowed the Tulane students to experience the environment of the public schools, while the field trip allowed the public-school students to experience a university setting and see laboratories.

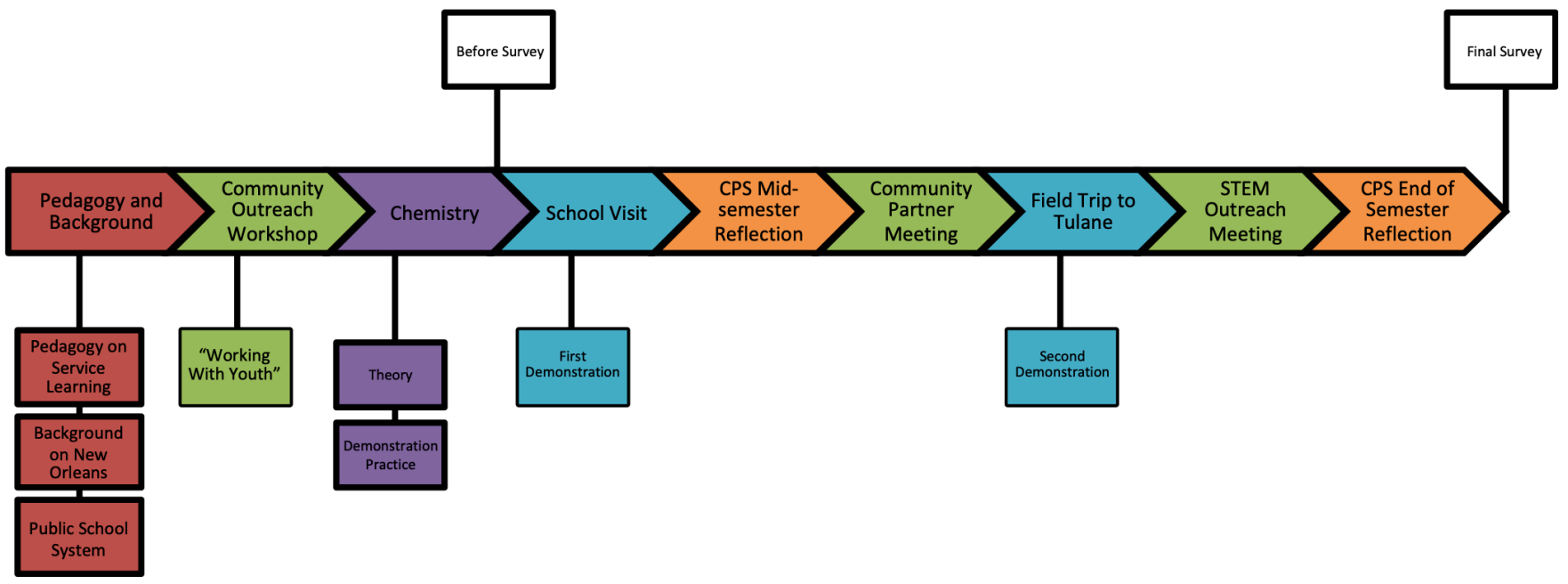

Figure 4. Course structure and timeline. 
The last subsection follows the Thonstrations and involves introspection on the service-learning activities. This was facilitated among the Tulane undergraduates by CPS led midterm (after the school visits) and end of semester (after the complete course) reflections. These in-class reflections were designed to help the undergraduate students consider the implications of their service and the problems that the community faces. The interactive discussions were on subjects such as preconceived expectations, anecdotes and opinions on the experience. It is important to note that these discussions were held in the absence of the graduate TAs or professor, allowing the students to discuss the course and

500 their experiences with the benefit of anonymity. The overall structure and timeline of the course is shown in Figure 4.

\section{Chemistry Demonstrations}

505 The undergraduate students had a choice among six demonstrations covering different aspects of chemistry. These demonstrations are illustrated in Figure 5 and a brief synopsis is provided below. The reader is also referred to the

510 Supplemental Section where the details and demonstration protocols are provided. The

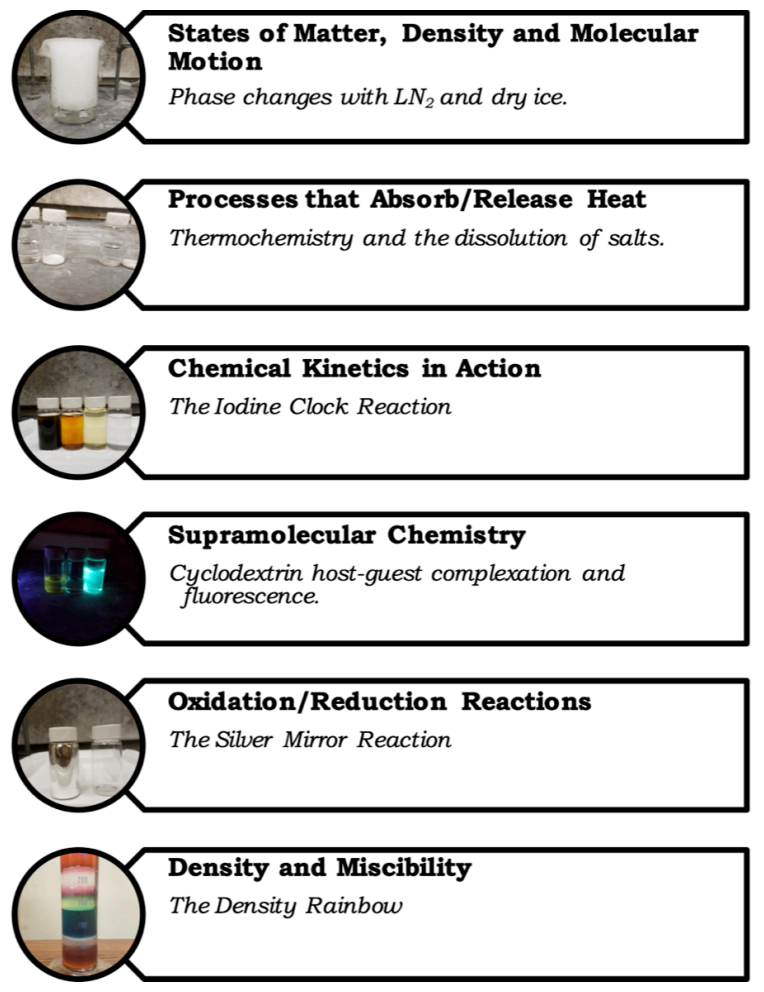

Figure 5. Chemistry topics and related topics. students were provided guidelines for the demonstrations and participated in TA led training sessions allowing each student to 515 practice every experiment in a safe location before the public-school demonstrations. Each student chose one of the six demonstration and created a presentation that could be easily modified based on the age group and presentation space at the community partner location. The undergraduate students also were asked to make the demonstrations interactive such that the public school students could partcipate and get hands-on experience in some aspect of the demonstrations.

Before the school visits, a group of 3 or 4 undergraduate students practiced their demonstrations as a cohesive unit. Following their preparation, the students were chaperoned
530

535 by one or more graduate TAs to the schools, where they had a ca. 1.5-hour timeframe to conduct their demonstrations. The overall time commitment for demonstrations was typically 3 hours including travel to the venues and set-up time. At the service-learning sites, each undergraduate student received the opportunity to both lead their primary demonstration and assist with the demonstrations being conducted by their peers.

The second chemistry demonstration component that the students participated in was associated with a field trip, where students from one of the partner schools came to Tulane for a chance to see the chemistry research laboratories. Here the public-school students were exposed to demonstrations that were either regarded as sufficiently dangerous that they needed to be conducted in a laboratory setting with appropriate engineering controls or were unable to be transported to the schools. These demonstrations were performed by graduate students and included manipulating LASERs, combusting gummy bears in a pure oxygen environment generated from potassium chlorate, and generating oscillating fluorescence using organometallic complexes. During this trip, the undergraduates each performed a second different demonstration for the visiting students to supplement the demonstrations the graduate students were performing.

When preparing for their demonstrations, the undergraduate students had to consider the age range of the school students they were visiting. Not only did the undergraduates need to understand the chemical concepts, but they 
also needed to convey this knowledge to the younger students. This practice served to reinforce the understanding of chemistry by the Tulane students. Some examples of 570 explanations of concepts or replacement definitions for chemical terminology that the undergraduate students formulated are presented in Supplemental Table 1. The undergraduate students discussed concepts 575 related to real world examples, visual representations, and common compounds already familiar to the K-12 students.

States of Matter, Density and Molecular

Motion: Phase changes with liquid nitrogen $\left(L N_{2}\right)$ and dry ice. (Adapted from George Stanley and Patrick Limbach $)^{45}$

This experiment allowed the undergraduate students to demonstrate phase changes, flash freezing, and gas contraction/expansion via a dry ice filled balloon or glove. The undergraduate students were able to link familiar phase changes such as melting, freezing, and boiling to the less familiar sublimation process of dry ice. One of the most visually stimulating components of this demonstration is when the students are given the chance to blow soap bubbles on top of the sublimating dry ice. This experiment also provided a vehicle to explain the concept of density. Condensation is a recurring theme during this demonstration (i.e., $\mathrm{LN}_{2}$ condensing higher-boiling gasses from the air as it falls to the floor). This demonstration also expanded on the concept of boiling. The undergraduate students explained that many substances boil at temperatures that are cold, as opposed to hot. This was demonstrated through $\mathrm{LN}_{2}$. The $\mathrm{LN}_{2}$ was also used to flash freeze different objects such as flowers.

Processes that Absorb/Release Heat: Thermochemistry and the dissolution of salts. (Adapted from Bassam Shakhashiri) ${ }^{46}$

This demonstration uses salts (lithium chloride and ammonium nitrate) commonly found in hot and cold packs to represent thermochemistry in a relatable way. The concepts of exothermic and endothermic processes were explained using real-world comparisons to hot and cold packs. This related the chemistry theory to applications (e.g., treating sports injuries) that the school students were familiar with and could readily relate to.
620

\section{Chemical Kinetics in Action: The Iodine Clock} Reaction (Adapted from Bassam Shakhashiri) 46

This experiment visually represents the 625 concentration on reaction rate. In particular, the rate of the color change in the iodine clock reaction is dependent on the concentration of the reacting species with the color change occurring faster with higher concentration. The Tulane students discussed concentration in terms of amount of people in a room, comparing the reaction rate to a game of tag with low concentration comparable to a game with few people playing and high

635 concentration involving many people. It is faster to catch someone with more people playing than less, much like a reaction will occur faster with more molecules.

Supramolecular Chemistry: Cyclodextrin hostguest complexation and fluorescence. (Adapted from Brian D. Wagner, Penny J. MacDonald, Maryam Wagner and Thomas A. Betts) ${ }^{47}$

This demonstration introduces the concept of host-guest binding in supramolecular chemistry as well as the concept of fluorescence. In particular, the interaction of a host (hydroxypropyl $\beta$ cyclodextrin) and guest (8650 anilino naphthalene sulfonic acid, ANS) results in strongly enhanced fluorescence of the ANS. Supramolecular chemistry is an advanced topic that can be difficult to understand. However, relating supramolecular chemistry to molecular 655 interactions in biology and representing the host and guest with a literal cup and ball helped the school students visualize the idea.

Oxidation/Reduction Reactions: The Silver 660 Mirror Reaction (Adapted from Bassam Shakhashiri) ${ }^{46}$

This experiment introduced the concept of oxidation/reduction reactions by using the precipitation of silver from its ionic form onto the sides of a glass vial. This experiment connected how electrons functioned in reactions involving oxidation or reduction. The change from silver nitrate to elemental silver demonstrates the idea 670 of a redox reaction whilst providing an aweinspiring moment when the formerly colorless solution plates the glass vial with a silver mirror. 

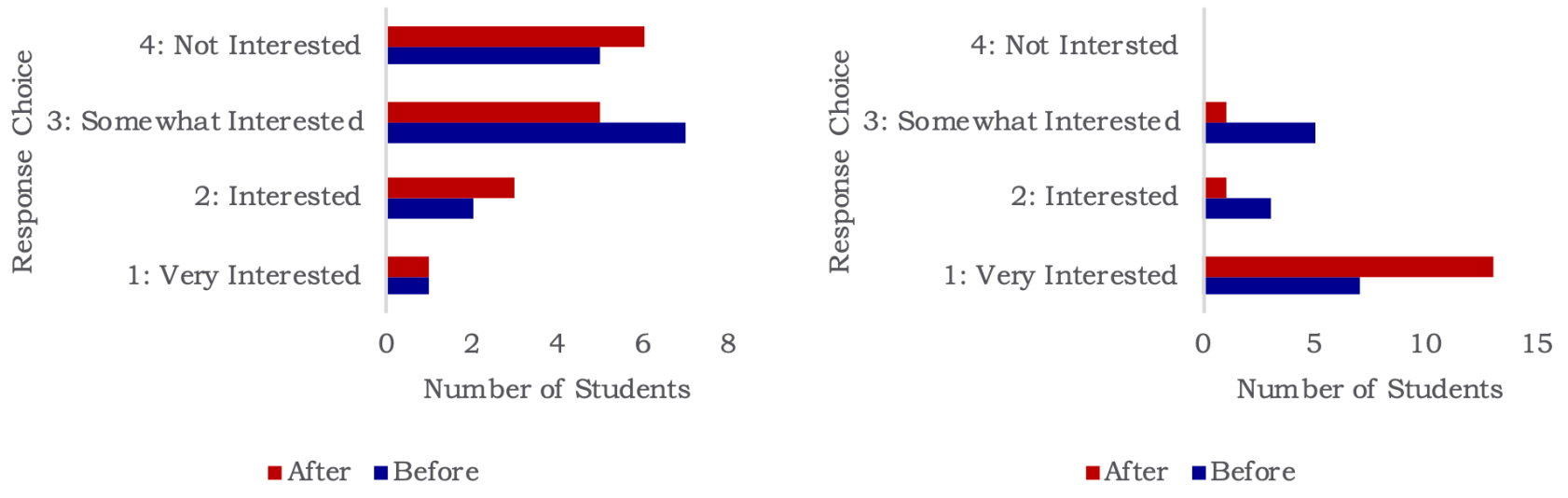

Figure 6. Measuring Interest in Career Options (a) Chemistry career Interest: comparisons of before and after surveys Response Choices 1: Very interested in pursuing a chemistry career path 2: Interested in pursuing a chemistry career path. 3: Somewhat Interested in pursuing a chemistry career path 4: Not interested in pursuing a chemistry career path. (b) Chemistry adjacent Career: comparison of before/after surveys regarding interest in pursuing a career in something related to chemistry with response choices: 1: Very interested 2: Interested 3: Somewhat Interested 4: Not interested

Density and Miscibility: The Density Rainbow (Adapted from Steve Spangler) ${ }^{48}$

This demonstration visually represents the concept of density in a colorful manner and shows how miscibility can affect the mixing or (lack thereof) of different substances. The terms of hydrophobicity and hydrophilicity were explained using layman language associated with 'philic' and 'phobic' in addition to using examples such as oil and water.

\section{RESULTS AND DISCUSSION}

The results from the course were evaluated in terms of outcomes for the undergraduate students and graduate student TAs. The undergraduates were surveyed on their selfefficacy and interest in STEM as well as interest in community engagement. Graduate student outcomes were evaluated through anecdotal experiences.

\section{Methodology}

The undergraduates were evaluated with a paired set of anonymous before and after surveys to gauge their development as the course progressed and also to determine if there were any changes in their mindsets about topics ranging from future career choices to confidence in their mastery of chemical concepts. The surveys and complete data are attached in the SI. The before survey was administered to the students following the completion of the lecture and practice demonstration portions of the class (prior to their visit to the local schools). The after-survey was administered to the 710 undergraduates following the conclusion of their final reflection. In questions that were paired together, analysis was done via a one-tailed student t-test for a paired sample.

715 Undergraduate Student Outcomes

The students who take CHEM 1898 course are typically pre-medical scholars. Hence, it would follow that few would readily change their entire career path after this one course. Indeed, as can 720 be seen in the pre and post survey results shown in Figure $6 a$ the interest in chemistry careers is low and does not change appreciably as a function of taking the service-learning course. In contrast, from the questions gauging their 725 interest in pursuing chemistry related careers, it was found that the students became much more certain about joining a career that is adjacent to chemistry (i.e. doctor, chemical engineer). As can be seen in Figure $6 \mathrm{~b}$ in the after-survey, 6 730 (out of 15) more students indicated that they were very interested in pursuing a career in a chemistry adjacent field. These results make us suggest that the course enhanced the students' motivation in STEM careers (albeit not in pure 735 chemistry). Furthermore, such an increase was encouraging since this class was composed of mainly females $(80 \%)$, a group that is typically 
under-represented in STEM fields ${ }^{11}$. Additionally, several students noted that they working with young students and could see themselves working with children, in a teaching capacity or otherwise.

In addition to the increase in resolve to remain in STEM fields, the undergraduate students expressed increased confidence in all, or most chemistry concepts presented in CHEM 1898 when compared to a standard general chemistry lab course (Figure 7). What is striking is a couple of students even mentioned that they had no confidence in concepts learnt in general chemistry laboratory.

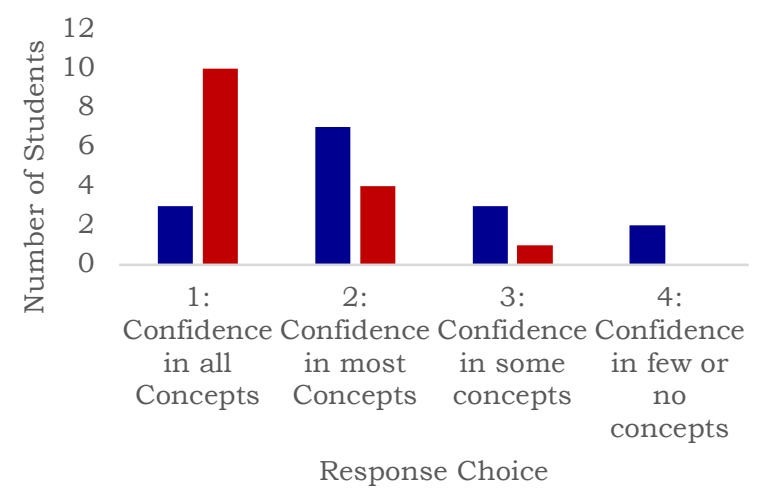

-General Chemistry - Service Learning Course

Figure 7. Undergraduate Student Confidence in their retention of chemistry concepts based on the source.

Beyond just enhancing material learning, students were also assessed on their development in other areas. In further assessment, students were surveyed on their interest in participating in future community outreach and a modest change was observed (see Figure S2). Out of 15 students, 3 more students assessed themselves as being more likely to participate in community outreach in the future. This small change in addition to the high baseline interest could be possibly explained by the fact that Tulane is a pioneering terms of focusing on service and thus many students choose to come to Tulane, in part, because of their own interest in community outreach. This change was accompanied by a modest increase in the number of students indicating that they felt at least somewhat connected to the surrounding community (Figure S3).

Another aspect the students were assessed on was their comfort with public speaking. The students in this class were already quite confident in public speaking: a majority of the students indicated that they already felt comfortable in speaking to a large audience. However, of those that were less confident, they 780 indicated at least some improvement in their mindset towards public speaking after the course (Figure S4). Most of these students indicated the course helped them feel more comfortable in small or medium sized settings, 785 or that they now felt more prepared to rephrase ideas when necessary.

\section{Graduate Student TA Outcomes}

None of the TAs had prior background in leading 790 a service-learning course. All the TAs initially became involved with the course, in part, to fulfill the mandate for service from their Louisiana Board of Regents fellowships, but all TAs continued participating in the course after 795 their fellowship period expired.

The TAs of this course were given multiple leadership opportunities. The TAs designed and delivered the pedagogy and history lectures to the undergraduates. They also were required to 800 design and alter the chemistry demonstrations and lessons. The TAs originally aided in finding community partners, and after the initiation of a partnership with CPS, the TAs acted as liaisons between the course and the CPS based workers.

This course enabled the TAs to gain academic and pedagogical experience beyond their research focus on supramolecular chemistry. The TAs also gained interpersonal 810 and management skills as a result of working in a large collaborative setting with undergraduate students, community members, and school students-which is in contrast to skills learnt from a TA assignment in a typical chemistry

815 course. In addition to this, involvement with the course encouraged the graduate TAs to explore pedagogy, a rare opportunity for typical graduate students in chemistry.

\section{CONCLUSION}

We have described a chemistry centered servicelearning course taught at Tulane in the city of New Orleans. This course was aimed at enhancing student interest and self-efficacy in STEM. The course has been offered at Tulane since 2009 The Spring 2019 iteration of the course involved a diversified curriculum, including general chemistry and supramolecular chemistry concepts and 
corresponding eye-catching demonstrations. student thinking and discussion on the need for STEM-related service and examining the societal reasons that have led to this need. The course also combined community partner led discussions and worked with the Tulane CPS that offered key logistical support (e.g., student preparation prior to entering the community and help with establishing community partnerships).

CHEM 1898 also incorporated multiple student surveys and these evaluations lead us to suggest that the undergraduate students had an enhanced desire to pursue STEM careers (albeit not in pure chemistry). Importantly, in general, the students expressed high confidence in the retention of the chemistry concepts that the course focused on, in contrast to concepts retained from a standard general chemistry lab course. In addition, the service-learning experience increased student comfort in working with children. There was also a modest increase in encouraging future community outreach by the undergraduate students, however, these students were already very likely to conduct community outreach projects.

In conclusion, CHEM 1898 is a well-rounded chemistry-based service-learning course designed to provide undergraduate students, graduate students, and the surrounding community an opportunity to effectively collaborate on a mutually beneficial project that strengthens the resolve to join or continue with STEM and raises the enthusiasm of all involved. We believe that this type of chemistry-based service-learning course can be readily adapted to help other universities interested in enhancing student interest and self-efficacy in STEM whilst also developing strong partnerships with the outlying community.

\section{ASSOCIATED CONTENT}

Supporting Information

The Supporting Information is available on the ACS Publications website at DOI: 10.1021/acs.jchemed.
Notes for Instructors (DOCX)

Survey Instrument (DOCX)

\section{AUTHOR INFORMATION}

Corresponding Author

*jananj@tulane.edu
880

\section{ACKNOWLEDGMENTS}

The authors are grateful for the aid and support that Tulane's Center for Public Service has provided this course in advice, finding 885 partnerships, and helping to support the funding of the demonstration materials. We appreciate Cliff Nelson for the iodine clock demonstration he designed. We also thank the undergraduate students, the teaching 890 assistants, and our community partners in the participating schools. The support from the K12 STEM outreach program at Tulane has provided in affording us contacts and additional opportunities for service is greatly appreciated. This work was supported by the NSF (Grant CHE 1609603 to J.J.) which provided funding for this program. The Louisiana Board of Regents Fellowship is thanked for supporting the graduate TAs.

\section{REFERENCES}

(1) Alexandria, V. National Science Board. 2018. Science and Engineering Indicators 2018. NSB-2018-1.

(2) Smithsonian Science Education Center. The STEM Imperative. https://ssec.si.edu/stem-imperative (accessed Aug 2019).

(3) Emerson US. 2 in 5 Americans Believe the STEM Worker Shortage is at Crisis Levels. https://www.emerson.com/enus/news/corporate/2018-stem-survey (accessed Aug 2019). India - Surya, N. The Skills Gap in U.S. Manufacturing 2015 and Beyond. Report for The Manufacturing Institute and Deloitte. 2015.

Giffi, C.; Wellener, P.; Dollar, B.; Manolian, H.A.; Monck, L.; Moutray, C. 2018 Deloitte and The Manufacturing Institute Skills Gap and Future of Work Study. Report for The Manufacturing Institute and Deloitte.2018.

(6) Lichtenstein, G.; Loshbaugh, H.; Claar, B.; Bailey, T.; Sheppard, S. Should I Stay or Should I Go? Engineering Students' Persistence If Based on Little Experience or Data. Am. Soc. Eng. Educ. 2007, 2427.

(7) Toven-Lindsey, B.; Levis-Fitzgerald, M.; Barber, P. H.; Hasson, T. Increasing 
Persistence in Undergraduate Science Majors: A Model for Institutional Support of Underrepresented Students. CBE-Life Sci. Educ. 2015, 14 (2), ar12. https://doi.org/10.1187/cbe.14-050082.

(8) Chen, X. (2013). STEM Attrition: College Students' Paths Into and Out of STEM Fields (NCES 2014-001). National Center

(9) Lent, R. W.; Brown, S. D.; Hackett, G. Education Sciences, U.S. Department of Education. Washington, DC, November 2013. Toward a Unifying Social Cognitive Theory of Career and Academic Interest, Choice, and Performance. J. Vocat. Behav. 1994, 45 (1), 79-122. https://doi.org/10.1006/jvbe.1994.102 7.

(10) Perez, A. Valuing STEM Majors: The Role of Occupational-Academic Ego-Identity Status and Task Values in STEM Persistence, 2012.

(12) Cohen, R.; Kelly, A. M. Community College Chemistry Coursetaking and STEM Academic Persistence. J. Chem. Educ 2019, 96, 12.

(15) Liu, Y.; Raker, J. R.; Lewis, J. E. Evaluating Student Motivation in Organic Chemistry Courses: Moving from a Lecture-Based to a Flipped Approach with Peer-Led Team Learning. Chem. Educ. Res. Pract. 2018, 19 (1), 251-264.
(16)

Frey, R. F.; Fink, A.; Cahill, M. J.; McDaniel, M. A.; Solomon, E. D. Peer-Led Team Learning in General Chemistry I: Interactions with Identity, Academic Preparation, and a Course-Based Intervention. J. Chem. Educ. 2018, 95 (12), 2103-2113. https://doi.org/10.1021/acs.jchemed.8 b00375.

$995 \quad(17)$

Lynette R. Goldberg; Richburg, C. M.; Wood, L. A. Active Learning Through Service-Learing. Commun. Disord. Q. 273 2006, 27 (3), 131-145.

(18) Freeman, S.; Eddy, S. L.; McDonough, M.; Smith, M. K.; Okoroafor, N.; Jordt, H.; Wenderoth, M. P. Active Learning Increases Student Performance in Science, Engineering, and Mathematics. Proc. Natl. Acad. Sci. 2014, 111 (23), 8410-8415.

https://doi.org/10.1073/PNAS.1319030 111.

(19) Furco, A. Service-Learning: A Balanced Approach to Experiential Education The Service-Learning Struggle; 1996.

(20) Trout, J. J.; Murphy, C.; Vukicevich, M. Combining Active Learning Techniques and Service Learning in a Section of Physics I with Calculus Course. Cit. Phys. Teach. 2019, 57, 109. https://doi.org/10.1119/1.5088473.

(21) Saltmarsh, J. Changing Pedagogies; pp 331-352; 2010.

(22) Astin, A. W.; Vogelgesang, L. J.; Ikeda, E. K.; Yee, J. A. How Service Learning Affects Students; Higher Education Research Institute University of California: Los Angeles, CA, January, 2000.

(23) Mesa Community College. Engaging Humanities: Interdisciplinary Approaches to Composition and ServiceLearning.

https://www.mesacc.edu/communitycivic-engagement/journals/engaginghumanities-interdisciplinaryapproaches-composition-and (accessed Aug 2019).

(24) Mogk, D. W.; King, J. L. Service Learning in Geology Classes. J. Geol. Educ. 1995, 43 (5), 461-465. https://doi.org/10.5408/0022-136843.5.461.

(25) Leega, Lissa; Cawthorn, M. Environmental Service Learning: Relevant, Rewarding, and Responsible, 
Journal of College Science Teaching, 2008-Jul. ERIC 2008, 37 (6), 32-36.

(26) Najmr, S.; Chae, J.; Greenberg, M. L.; Bowman, C.; Harkavy, I.; Maeyer, J. R. A Service-Learning Chemistry Course as a Model to Improve Undergraduate Scientific Communication Skills. J. Chem. Educ. 2018, 95 (4), 528-534. https://doi.org/10.1021/acs.jchemed.7

(28) Valuing Public Education: A 50 State Report Card. Report by The Network for Public Education. 2016.

(34) Center for Public Service. Graduation Requirement. 790.

Education.

https://www.usnews.com/news/best-

states/rankings/education (accessed 1110 Aug 2019).

Babineau, K.; Hand, D.; Rossmeier, V.; Hill, A. The State of Public Education in New Orleans. Report by The Cowen Institute; New Orleans, LA, 2018.

Digest of Education Statistics, 2014. Report by the National Center for 1120 Education Statistics, 2015. https://nces.ed.gov/programs/digest/d 16/tables/dt16_204.10.asp

The New Orleans Education Equity Index A Look at Educational Equity in New Orleans Public Schools. Report by Converge, in partnership with the Louisiana Center for Children's Rights (LCCR) and Orleans Public Education Netweork (OPEN), 2018.

W.P. III. Educators get $\$ 13$ million grant to recruit 900 teachers by 2020. The Times-Picayune [Online], Nov 14 , 2017. | https://www.nola.com/news/educatio n/article_76dd8c1f-33d6-5f39-8c9a504d6e9fb9e3.html. (accesed Aug 2019). Survival to Renewal: Tulane University. Tulane University Announces Bold Renewal Plan. http://renewal.tulane.edu/ (accessed Aug 2019).

https://cps.tulane.edu/about/graduatio n-requirement (accessed Aug 2019).

Center for Public Service. Service Learning Course. https://cps.tulane.edu/node/3286

(accessed Aug 2019).
Center for Public Service. https://cps.tulane.edu/ (accessed Aug 2019).

New Orleans Equity Index http://neworleansequityindex.org/schoo 1s / (accessed Jul 2019).

Barrett, N.; Harris, D. Significant Changes in the New Orleans Teacher Workforce; Brief by the Education Research Alliance for New Orleans; New Orleans, LA, August 2015.

Teach

New

Orleans.

https://teachneworleans.net/ourschools / (accessed Aug 2019).

Sentell, W. Louisiana's teacher shortage is real; here's what caused it, how state lawmakers look to solve it. The Advocate [Online], Mar 30,2018. https://www.theadvocate.com/baton_ro uge/news/education/article_cfOad3103375-11e8-99a3-

2b8866c895ad.html.(accesed Aug, 2019)

(41) Hasselle, D. Now an all-charter district, New Orleans schools experiment still faces questions. The TImes-Picayune [Online], Aug, 2019. https://www.nola.com/news/education /article_30fbef6e-b476-11e9-a3b557480c7a30f7.html (accessed Aug, 2019).

(42) Langhorne, E. New Orleans just made history for its education system. SunHerald [Online], July 6, 2018. https://www.sunherald.com/opinion/ar 1130 ticle214380924.html (accessed Aug, 2019).

(43) Schmidt, M.; Fulton, L. Transforming a Traditional Inquiry-Based Science Unit into a STEM Unit for Elementary PreService Teachers: A View from the Trenches. J. Sci. Educ. Technol. 2016, 25 (2), 302-315. https://doi.org/10.1007/s10956-0159594-0.

1140 (44) Registrar Tulane. Freshman Profile Fall 2018.

https://registrar.tulane.edu/sites/regist rar.tulane.edu/files/FTF_PROFILE_2018 .pdf. (accessed Aug 2019).

(45) Stanley, G.; Limbach, P. The Atmosphere: Liquid Nitrogen (LN 2 ), Liquid O 2 (LO 2 ), Solid CO 2 (Dry Ice) \& Water Vapor. https://www.lsu.edu/science/chemistry /news/spotlight/chem_demo/Demo-1atmosphere-LN2.pdf (accessed Aug 
2019).

(46) Shakhashiri, B. Z. Chemical Demonstrations: A Handbook for Teachers of Chemistry; University of Wisconsin Press: Madison, Wis., 1983; Vol. 1-5.

(47) Wagner, B. D.; MacDonald, P. J.; Wagner, M. A Visual Demonstration of Supramolecular Chemistry: Observable Fluorescence Enhancement Upon GuestHost Inclusion. J. Chem. Educ. 2000, 77, 178-181.

(48) Steve Spangler Science. Amazing 9 Layer Density Tower - SICK Science!. 1165 https://www.stevespanglerscience.com/1 ab/experiments/density-tower-magicwith-science/ (accessed Aug 2019). 